\title{
Antipredator behaviour of domestic guinea pigs (Cavia porcellus)
}

\author{
Aneta Baklová1, Eva Baranyiová1,2, Hana Šimánková ${ }^{3}$ \\ ${ }^{1}$ Czech University of Life Sciences in Prague, Faculty of Tropical AgriSciences, \\ Department of Animal Science and Food Processing, Prague, Czech Republic \\ ${ }^{2}$ Veterinary Research Institute Brno, Czech Republic \\ ${ }^{3}$ Charles University in Prague, Institute of Zoology, Prague, Czech Republic
}

Received July 1, 2016

Accepted August 31, 2016

\begin{abstract}
The objective of this study was to test the reactions of domestic guinea pigs to the presence of aerial and terrestrial predators in a laboratory setting. We measured the behavioural reactions of 27 adolescent guinea pigs to the presence of a dog, imitation of a bird of prey and an unknown human as control. Kruskal-Wallis ANOVA and Mann-Whitney U Test were used to analyse the differences in duration and frequency of responses (freezing, fleeing, and vigilance) to predators. When confronted with the dog, guinea pigs reacted for the longest time and most frequently by freezing. In presence of the bird of prey, they responded for the longest time and most often by freezing and fleeing. In presence of a human, they showed mostly vigilance. When comparing reactions to the dog and human, there were differences in duration and frequency of freezing and fleeing. When comparing reactions to the bird of prey and control test, we observed differences between fleeing and vigilance. The durations and frequencies of freezing, fleeing and vigilance to the dog and bird of prey were different. The only differences in reactions of males and females occurred in duration and frequency of fleeing in presence of the bird of prey. No vocalization was observed except for two occurrences, of a "drrr" and a "chirrup". Our results indicate that domestic guinea pigs tested under laboratory conditions can discriminate between a terrestrial and an aerial predator, when exposed to them individually. Their antipredator behaviours remained functional, although their vocalizations may have been affected by the absence of signal receivers.
\end{abstract}

Vigilance, freezing, fleeing, duration, alarm call

Feral ancestors of domestic guinea pigs (Cavia porcellus Linnaeus, 1758) are wild cavies (Cavia aperea Erxleben, 1777), the neotropical, herbivorous and diurnal rodents (e.g. Cassini 1991). Cavies live in bushy and grassy lands near to rivers and lakes of South America (Ximénez 1980; Asher et al. 2004). Cavies spend the majority of daytime foraging close to shelters. When a predator appears, they run, hide in shelter, and freeze (e.g. Rood 1972). Wild cavies also vocalize to warn conspecifics and to intimidate the predator (Berryman 1976; Monticelli and Ades 2013).

Predators attack cavies from the air, on the ground, and from the water (As her et al. 2004). The main mammalian predators of cavies include the fox Cerdocyon thous (Canidae) and the minor grison Galictis cuja (Mustelidae) (G a m ba r ot t a et al. 1999). Other predators of cavies include the little water opossum Lutreolina crassicaudata (Didelphidae); raptors Milvago chimango, Polyborus plancus (Falconidae), Circus cinereus, Circus buffoni, Buteo magnirostris (Accipitridae), and Bubo virginianus (Strigidae), as well as snakes such as Philodrya spatagoniensis (Colubridae) (Gambarotta et al. 1999).

Guinea pigs were domesticated approximately 3,000-6,000 years ago (e.g. Hücking haus 1961 ) but as other authors indicate, up to 7,500 years ago in the Andean region (e.g. Wing 1986). Unlike for cavies, there is practically no threat of a predator attack for domestic guinea pigs living under human-made conditions. They have become one of the most popular pet species as well as common laboratory animal owing to their mild character,

Address for correspondence:

MSc. Aneta Baklová

Department of Animal Science and Food Processing

Faculty of Tropical AgriSciences

Czech University of Life Sciences in Prague

Kamýcká 961/129, 16521 Prague 6, Czech Republic

Phone: +420 773973397

E-mail: antenka@email.cz

http://actavet.vfu.cz/ 
a result of the domestication process. In guinea pigs, this long-term evolutionary process has been accompanied by decreased alertness, nervousness, and sensitivity (e.g. Rood 1972). Guinea pigs also show less explorative behaviour (Künzl et al. 2003; Zipser et al. 2014) and they are, like other domestic animal species, generally more tolerant and less aggressive to conspecifics than their wild ancestors (e.g. Herre and Röhrs 1990).

To our knowledge, no data are available on the antipredator response in domestic guinea pigs. We therefore investigated how guinea pigs react to the presence of predators. We hypothesise that, similar to wild cavies, they can distinguish between several types of predators.

\section{Animals}

\section{Materials and Methods}

For the experiments, 27 laboratory short-haired guinea pigs (14 males, 13 females) aged 10-12 weeks were used. The experiments took place in the Demonstration and Experimental Stable (authority number 58176/2013-MZE17214) of the Czech University of Life Sciences in Prague. All guinea pigs were kept indoors at a temperature of $19{ }^{\circ} \mathrm{C} \pm 2{ }^{\circ} \mathrm{C}$ with relative humidity in the room of about $54 \% \pm 3 \%$ and natural daylight. Guinea pigs were divided into six groups of four individuals assembled by sex; three animals were caged individually. They were kept in polypropylene cages $(54 \times 39 \times 20 \mathrm{~cm})$. Water was provided ad libitum, pellets and fresh vegetables once a day in the morning except the days of the test, because we wanted to keep them in alertness. The animals were individually identified through the natural colours of their fur. White animals were marked by colour symbols.

Data collection

Data were collected during September and November 2013. The recording took place during morning hours between 8:00 and 10:00 $\mathrm{h}$ before feeding, when the animals were active. Each animal was separated from other members of the group and placed into a $40 \times 30 \times 40 \mathrm{~cm}$ open field arena (glass box) without litter, food or water. The box was placed in an acoustically insulated room, where no auditory or visual contact with other guinea pigs was possible. The digital recorder was located $30 \mathrm{~cm}$ above the floor; the digital camera was located $150 \mathrm{~cm}$ above the box.

Each experimental session took $2 \mathrm{~min}$ and the behavioural reactions and vocalization were recorded simultaneously. Each guinea pig was exposed to two predators - terrestrial (carnivorous mammalian predator) and aerial (taxidermy bird of prey with spread wings). For each type of activity, its frequency (number of occurrences of the respective behaviour) and duration (length of behaviour) were analysed. The results were expressed as percentage of the test period.

The terrestrial predator was represented by a female border collie, and the aerial model of a predator was represented by tawny owl (Strix aluco) of the order Strigiformes. In the first part of the trial, the dog walked around the box with each guinea pig at a distance of about $20-40 \mathrm{~cm}$ from the box. The dog was not on a leash; its owner stood in the background around $4 \mathrm{~m}$ away and gave the dog verbal commands. The dog barked several times. During the second trial, the guinea pigs were exposed to the presence of a human. Guinea pigs were in regular contact with humans before our experiments; therefore, a person was used as a control test.

In the last part of the experiment, each guinea pig was exposed to contact with a taxidermy bird of prey. Our model was $30 \mathrm{~cm}$ long, with a wing span of and $75 \mathrm{~cm}$. A person was hidden behind a desk and moved the bird model using a $1.5 \mathrm{~m}$ long pole. This model was moved from side to side at approximately $1.5 \mathrm{~m}$ height above the box with the tested guinea pig. Vocalizations were recorded using the digital recorder Marantz Professional PMD 620 (manufacturer Marantz, Japan) (frequency response 20-20 $000 \mathrm{~Hz} \pm 1.0 \mathrm{~dB}$ ) with a sampling rate of $44.1 \mathrm{kHz}$ with a 16 bits sample size and a dynamic range $>87 \mathrm{~dB}$, and saved in the wav format. Behavioural reactions of guinea pigs were recorded by digital cameras JVC Everio GZ-GX1 (manufacturer JVC Kenwood, China) and Samsung HMX-F90 (manufacturer Samsung, Korea) in an avi file. A woman unknown to the animals walked slowly around the box in the same distance as the dog.

Each guinea pig was used only once for the individual predator type exposures on three consecutive days. On day 1, the trial with the dog took place; on day 2, the control test followed; and the influence of the raptor's presence was tested on day 3. The animals were tested one by one from No. 1 to No. 27.

The taped antipredator behaviour included flight, vigilance and freezing. These behaviours were defined as follows:

Fleeing: the individual runs trying to escape from the stimulus (Rood 1972; Shahaf and Eilam 2003; Taraborelli 2006).

Vigilance: alert posture with freezing and extended front legs and eyes directed toward the stimulus (Rood 1972; Taraborelli 2006).

Freezing: guinea pig staying immobile in a crouched posture (Rood 1972; Shahaf and Eilam 2003).

Analyses

All recorded calls were quantified by bioacoustical software Avisoft-SASLab Pro, version 5.2.07 (Avisoft Bioacoustics 2010). Sounds were visualized in spectrograms of the following parameters: FFT length: 512; frame 
size: 100\%; window: Hann; bandwidth: $129 \mathrm{~Hz}$; frequency resolution: $86 \mathrm{~Hz}$; overlap: $87.5 \%$. The behaviour of guinea pigs was analysed from the video-recordings using the software for behavioural studies Activities 2.1 (Vrba and Donát 1993). Final data were evaluated by the software Statistica 12 (Statsoft Inc. 2013). Non-parametric tests Kruskal-Wallis ANOVA, followed by Mann-Whitney U Test were used to analyse the reaction of individuals to each type of predator. The accepted significance level was $P<0.05$.

\section{Results}

After the individual tested animal was placed in the open field arena, it stayed at one place until the predator came into view. Each guinea pig maintained eye contact with the dog and observed the movements of the human. It was not able to notice the bird of prey, since it was out of its field of vision, until its shadow appeared on the ground.

\section{Males $\times$ females}

When testing differences in reactions between sexes, duration of fleeing was higher (Kruskal Wallis Test: $P=0.025$, df $1, \mathrm{~N}=27, \mathrm{H}=5.01$; Mann-Whitney U Test: $P=0.025$, $\mathrm{Z}=2.208)$ in females $\left(\widetilde{x}_{\text {duration }}=49 \mathrm{~s}, 40.83 \%\right)$ compared to males $\left(\widetilde{x}_{\text {duration }}=42.5 \mathrm{~s}, 35.41 \%\right)$ in presence of the bird of prey. Frequency of fleeing was also significantly higher (Kruskal Wallis Test: $\mathrm{p}=0.024$, df $1, \mathrm{~N}=27, \mathrm{H}=5.08$; Mann-Whitney U Test: $\mathrm{p}=0.029, \mathrm{Z}=2.159$ ) in females $\left(\mathrm{n}=13, \widetilde{x}_{\text {frequency }}=5\right)$ compared to males $\left(\mathrm{n}=14, \widetilde{x}_{\text {frequency }}=4\right)$ in presence of the bird of prey. No other significant differences occurred.

\section{Reactions to each stimulus}

Dog: In presence of the dog, guinea pigs reacted for a significantly shorter time (Kruskal Wallis Test: $P<0.001$, df $2, \mathrm{~N}=81, \mathrm{H}=50.95$ ), and less frequently (Kruskal Wallis Test: $P<0.001$, df $2, \mathrm{~N}=81, \mathrm{H}=49.78)$ by fleeing $\left(\widetilde{x}_{\text {duration }}=15 \mathrm{~s}, 12.50 \%, \widetilde{x}_{\text {frequency }}=2\right)$ than by vigilance $\left(\widetilde{x}_{\text {duration }}=50 \mathrm{~s}, 41.67 \%, \widetilde{x}_{\text {frequency }}=5\right)$ and freezing $\left(\widetilde{x}_{\text {duration }}=55 \mathrm{~s}, 45.83 \%\right.$, $\widetilde{x}_{\text {frequency }}=6$ ).

Moreover, $\widetilde{x}_{\text {duration }}$ of vigilance was significantly shorter (Mann-Whitney U Test: $P=0.020, \mathrm{Z}=2.327)$ than $\widetilde{x}_{\text {duration }}$ of freezing and $\widetilde{x}_{\text {frequency }}$ of vigilance was significantly more weakly (Mann-Whitney U Test: $P=0.012, Z=2.500$ ) than $\widetilde{x}_{\text {frequency }}$ of freezing.

Control (human) test: When confronted with the human, guinea pigs showed fleeing $\left(\widetilde{x}_{\text {duration }}=30 \mathrm{~s}, 25 \%, \widetilde{x}_{\text {frequency }}=3\right.$ ) for a significantly shorter time (Kruskal Wallis Test:

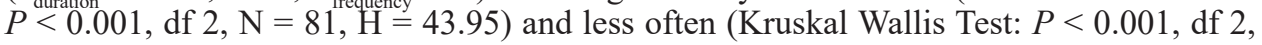
$\mathrm{N}=81, \mathrm{H}=36.99)$ than vigilance $\left(\widetilde{x}_{\text {duration }}=49 \mathrm{~s}, 40.83 \%, \widetilde{x}_{\text {frequency }}=5\right)$ and freezing $\left(\widetilde{x}_{\text {duration }}\right.$ $=41 \mathrm{~s}, 34.17 \%, \widetilde{x}_{\text {frequency }}=4$ ). Moreover, $\widetilde{x}_{\text {duration }}$ of vigilance was significantly higher (MannWhitney U Test: $P \stackrel{\text { frequency }}{=} 0.001, \mathrm{Z}=-3.322)$ than $\widetilde{x}_{\text {duration }}$ of freezing and $\widetilde{x}_{\text {frequency }}$ of vigilance was higher (Mann-Whitney U Test: $P=0.010, \mathrm{Z}=-2.560$ ) than $\widetilde{x}_{\text {frequency }}$ of freezing.

Bird of prey: In presence of the bird of prey, guinea pigs showed an attempt to flee $\left(\widetilde{x}_{\text {duration }}=44 \mathrm{~s}, 36.67 \%, \widetilde{x}_{\text {frequency }}=4\right.$ ) longer (Kruskal Wallis Test: $P<0.001$, df $2, \mathrm{~N}=81$, $\mathrm{H}=15.38$ ) and more frequently (Kruskal Wallis Test: $P=0.001$, df $2, \mathrm{~N}=81, \mathrm{H}=13.13$ ) than vigilance $\left(\widetilde{x}_{\text {duration }}=30 \mathrm{~s}, 25 \%, \widetilde{x}_{\text {frequency }}=3\right)$, and they showed vigilance for a significantly shorter time and less frequently than freezing $\left(\widetilde{x}_{\text {duration }}=46 \mathrm{~s}, 38.33 \%, \widetilde{x}_{\text {frequency }}=5\right)$. Duration and frequency of fleeing and freezing did not differ significantly (Mann-Whitney U Test: $P_{\text {duration }}=0.568, \mathrm{Z}_{\text {duration }}=0.571 ; P_{\text {frequency }}=0.478, \mathrm{Z}_{\text {frequency }}=0.709$, respectively).

Comparison of reactions to each stimulus

Dog $\times$ control (human) test: When we compared reactions of guinea pigs to the dog, our results showed shorter duration (Kruskal Wallis Test: $P<0.001$, df $1, \mathrm{~N}=54, \mathrm{H}=18.03$; $\widetilde{x}_{\text {duration }}=15 \mathrm{~s}, 12.5 \%$; Mann-Whitney U Test: $P<0.001, \mathrm{Z}=-4.230$ ) and lower frequency (Kruskal Wallis Test: $P<0.001$, df $1, \mathrm{~N}=54, \mathrm{H}=15.18$; $\widetilde{x}_{\text {frequency }}=2$; Mann-Whitney $\mathrm{U}$ Test: $P=0.000, \mathrm{Z}=-3.754$ ) of fleeing. When testing duration (Mann-Whitney U Test: 
$P=0.762, \mathrm{Z}=-0.303$ ) and frequency (Mann-Whitney U Test: $P=0.959, \mathrm{Z}=0.052$ ) of vigilance, we observed no difference in reaction to both stimuli. Duration (Kruskal Wallis Test: $P<0.001$, df $1, \mathrm{~N}=54, \mathrm{H}=15.58 ; \widetilde{x}_{\text {duration }}=55 \mathrm{~s}, 45.83 \%$; Mann-Whitney U Test: $P<0.001, \mathrm{Z}=3.927$, see Fig. 1) and frequency (Kruskal Wallis Test: $P<0.001$, df 1 , $\mathrm{N}=54, \mathrm{H}=18.22 ; \widetilde{x}_{\text {frequency }}=6$; Mann-Whitney U Test: $\left.P<0.001, \mathrm{Z}=4.074\right)$ of freezing was higher compared to those of the control test (fleeing: $\widetilde{x}_{\text {duration }}=30 \mathrm{s,}, 25 \%, \widetilde{x}_{\text {frequency }}=3$; freezing: $\widetilde{x}_{\text {duration }}=41 \mathrm{~s}, 34 \%, \widetilde{x}_{\text {frequency }}=4$ ).

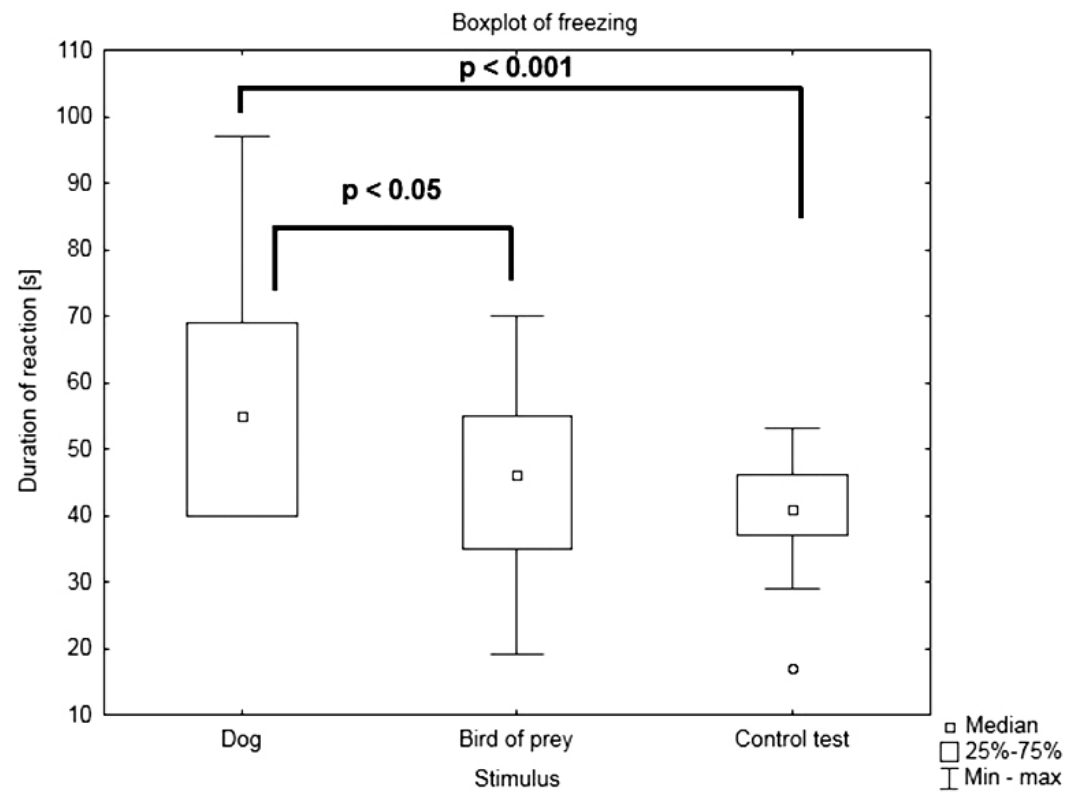

Fig. 1. Relationship between differences in duration of freezing to each type of predator. Significant difference (Mann-Whitney U Test: $P=0.000, \mathrm{Z}=3.927$ ) in reactions to the dog comparing to control test and between responses to the dog and bird of prey (Mann-Whitney $\mathrm{U}$ Test: $P=0.017, \mathrm{Z}=2.379$ ).

Bird of prey $\times$ control (human) test: In presence of the bird of prey, guinea pigs showed longer duration (Kruskal Wallis Test: $P=0.001$, df $1, \mathrm{~N}=54, \mathrm{H}=15.87 ; \widetilde{x}_{\text {duration }}=44 \mathrm{~s}$, 36.67\%; Mann-Whitney U Test: $P<0.001, \mathrm{Z}=3.970$, see Fig. 2) and higher frequency (Kruskal Wallis Test: $P=0.009$, df $1, \mathrm{~N}=54, \mathrm{H}=11.01 ; \widetilde{x}_{\text {frequency }}=4$; Mann-Whitney U Test: $P<0.001, Z=3.183)$ of fleeing in comparison with the control test $\left(\widetilde{x}_{\text {duration }}=\right.$ $30 \mathrm{~s}, 25 \%, \widetilde{x}_{\text {rrequency }}=3$ ). We observed significantly shorter duration (Kruskal Wallis Test: $P<0.001$, df 1 , N $=54, \mathrm{H}=23.60,25 \% ; \widetilde{x}_{\text {duration }}=30 \mathrm{~s}$; Mann-Whitney U Test: $P<0.001$, $\mathrm{Z}=-4.844$ ) and lower frequency (Kruskal Wallis Test: $P=0.000$, df $1, \mathrm{~N}=54, \mathrm{H}=21.16$, $\widetilde{x}_{\text {frequency }}=3$; Mann-Whitney U Test: $P<0.001, \mathrm{Z}=-4.463$ ) of vigilance compared to the control test $\left(\widetilde{x}_{\text {duration }}=49 \mathrm{~s}, 40.83 \%, \widetilde{x}_{\text {frequency }}=5\right)$. When testing the freezing to both stimuli, no significant differences occurred in either duration (Mann-Whitney U Test: $P=0.093$, $\mathrm{Z}=1.678$ ) or frequency (Mann-Whitney U Test: $P=0.183, \mathrm{Z}=1.332$ ).

$\operatorname{Dog} \times$ bird of prey: When confronted with the $\operatorname{dog}\left(\widetilde{x}_{\text {duration }}=15 \mathrm{~s}, 12.5 \%, \widetilde{x}_{\text {frequency }}=2\right)$, the tested animals showed fleeing for a shorter time (Kruskal Wallis Test: $P<0<001$, df 1 , $\mathrm{N}=54, \mathrm{H}=30.72 ; \widetilde{x}_{\text {duration }}=44 \mathrm{~s}, 36.67 \%$; Mann-Whitney U Test: $P<0.001, \mathrm{Z}=-5.519$ ) 


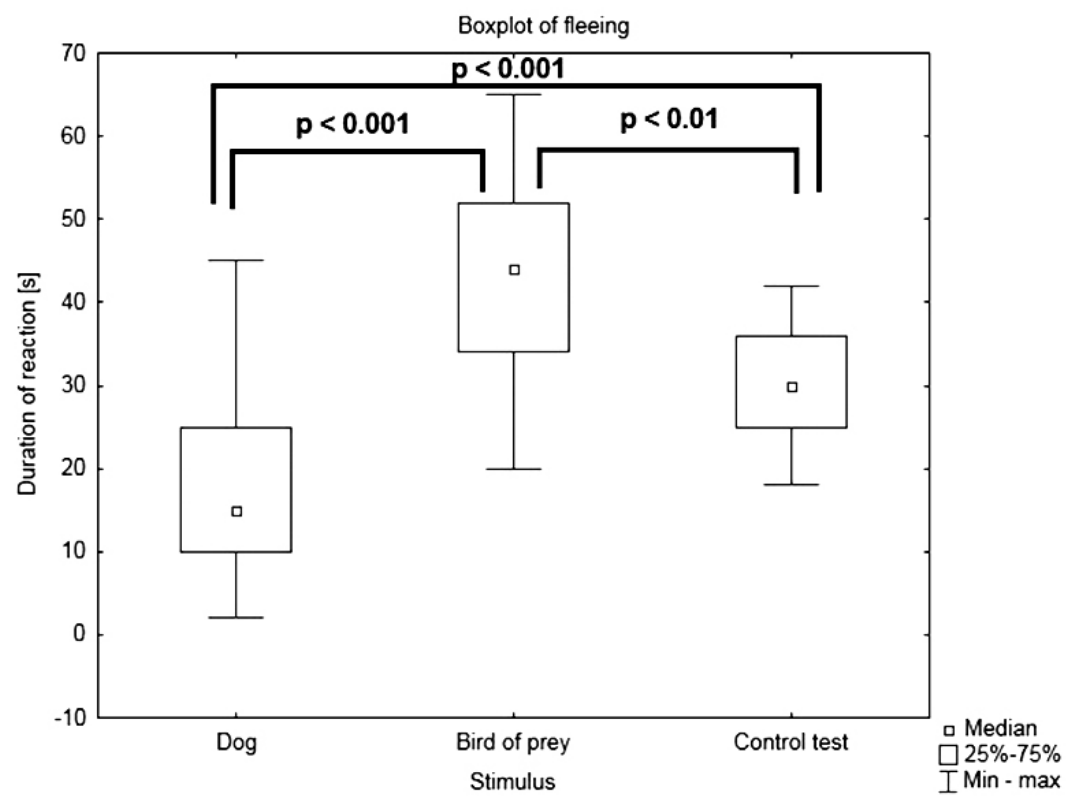

Fig. 2. Differences in duration of fleeing from each type of predator. Significant differences were found in each pair - dog and bird of prey (Mann-Whitney U Test: $P=0.000$, $\mathrm{Z}=-5.519)$, in bird of prey and control test (Mann-Whitney U Test: $P=0.000, \mathrm{Z}=3.970$ ) and in dog and control test (Mann-Whitney U Test: $P=0.000, Z=-4.230$ ).

and less often (Kruskal Wallis Test: $P<0.001$, df $1, \mathrm{~N}=54, \mathrm{H}=25.81 ; \widetilde{x}_{\text {frequency }}=4$; MannWhitney U Test: $P<0.001, \mathrm{Z}=-4.982$ ) than in the presence of the bird of prey. Duration of vigilance was longer in presence of the dog (Kruskal Wallis Test: $P<0.001$, df $1, \mathrm{~N}=54$, $\mathrm{H}=17.36$; $\widetilde{x}_{\text {duration }}=50 \mathrm{~s}, 41.67 \%$; Mann-Whitney U Test: $P<0.001, \mathrm{Z}=4.126$, see Fig. 3 ). Vigilance was noticed more often in response to the $\operatorname{dog}$ (Kruskal Wallis Test: $P<0.001$, df $1, \mathrm{~N}=54, \mathrm{H}=17.33 ; \widetilde{x}_{\text {frequency }}=5$; Mann-Whitney $\mathrm{U}$ Test: $\left.P<0.001, \mathrm{Z}=4.014\right)$ than to the bird of prey $\left(\widetilde{x}_{\text {duration }}=30 \mathrm{~s}, 25 \%, \widetilde{x}_{\text {frequency }}=3\right)$. In presence of the dog, guinea pigs reacted by freezing for a significantly longer time (Kruskal Wallis Test: $P=0.017$, df $1, \mathrm{~N}=54$, $\mathrm{H}=5.74 ; \widetilde{x}_{\text {duration }}=55 \mathrm{~s}, 45.83 \%$; Mann-Whitney U Test: $P=0.017, \mathrm{Z}=2.379$ ) and more often (Kruskal Wallis Test: $P=0.010$, df $1, \mathrm{~N}=54, \mathrm{H}=6.83 ; \widetilde{x}_{\text {frequency }}=6$; Mann-Whitney $\mathrm{U}$ Test: $P=0.011, \mathrm{Z}=2.552)$ than to the bird of prey $\left(\widetilde{x}_{\text {duration }}=46 \mathrm{~s}, 38.33 \%, \widetilde{x}_{\text {frequency }}=5\right)$.

\section{Alarm call}

Only two guinea pigs reacted to presence of a predator by vocalizing. In the first case, in reaction to the dog, the alarm call "drrr" (Plate VIII, Fig. 4A) occurred. In the second case, one guinea pig emitted the alarm whistle "chirrup" (Plate VIII, Fig. 4B) when detecting the taxidermy bird of prey.

\section{Discussion}

The ability of prey species to recognize predators is important for decreasing the predation risk (Lima and Dill 1990). This discrimination is ensured by both innate and learned mechanisms (Hollén and Radford 2009; Brown et al. 2013). It is well- 


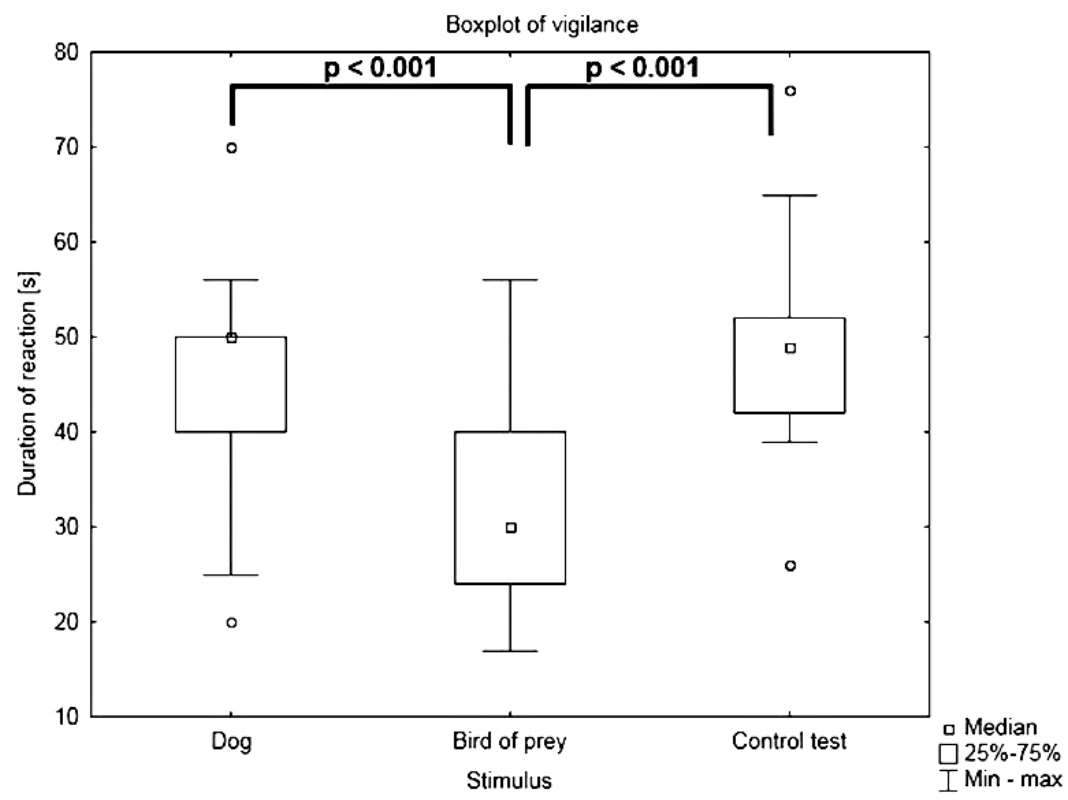

Fig. 3. Variations in duration of vigilance to each type of predator. Significant differences in bird of prey in comparison with control test (Mann-Whitney U Test: $P=0.000, Z=-4.844$ ) and in dog and bird of prey (MannWhitney U Test: $P=0.000, Z=4.126)$.

known that the predation risk increases in open areas (Lima 1987). Typical responses of rodents to predators include fleeing, vigilance, and freezing but also avoidance and hiding from threat (e.g. Shahaf and Eilam 2003). An open field does not provide any shelter; freezing is a form of hiding in the open space (Csányi et al. 1985). Freezing posture decreases the likelihood of being seen or heard by the predator (Curio 1976), and it is a defensive mechanism occurring when a relatively distant threat by a predator is perceived (Blanchard et al. 1990). The animal is immobile, its heart rate decreases, and it shows vigilance to the threat. Also a recent human study suggests that freezing is not a helpless anticipation but rather an active preparation to respond to a threat (Gladwin et al. 2016). On the other hand, tonic immobility (playing dead) is an innate physical inactivity (e.g. Klemm 2001) shown in cases of extreme threat, e.g. in a direct tactile prey confrontation (e.g. Gallup et al. 1977; Blanchard et al. 1986). The behaviour in our experiment was evaluated as freezing; the tested animal was frozen only during the testing period. Nevertheless, possible effects of stress caused by separation from its group, the coldness of glass surface or the fact that the trials took place in sequence during three subsequent days cannot be ruled out. Although after their first experience in the open field arena the animals may have habituated somewhat to the procedure, they still showed freezing.

When the guinea pigs were confronted with the dog, the number of occurrences and frequency of freezing was high. Apparently, the guinea pigs perceived the dog as a threat and they took up the strategy of freezing in order to avoid being noticed by the dog in the open area. Guinea pigs could identify the terrestrial predator by vision and olfaction. Sources of odour are e.g. fur, skin, and secretion of the anal glands. Many mammalian species are able to distinguish odours of predators (Apfelbach et al. 2005). Pongrácz and 
Altbäcker (2000) described antipredator responses in young (5-8 weeks old) and adult (6-9 months old) rabbits to presence of a fox under laboratory conditions. Adult rabbits tried to flee ahead of the predator unlike young rabbits which primarily froze (Pongrácz and Altbäcker 2000). Apparently, age is a crucial element in the avoidance response of prey, and we can expect changes in the antipredator response even in guinea pigs due to time and experiences during ontogeny.

When exposed to the human, the tested guinea pigs showed vigilance for the longest time. This behaviour is characterised by a static posture with extended legs and head up which allows visual scanning of the environment to distinguish between a threat and a non-dangerous event (Cassini 1989). An experiment with rabbits showed that rabbits handled by a human beware less of humans compared to non-handled rabbits (Pongrácz and Altbäcker 1999). It is well-known that vigilance with a human may be a sign of food and contact anticipation. In our case, this reaction may have been intensified by the absence of feeding in the morning.

The tested guinea pigs exposed to the model of a bird of prey most of the time exhibited fleeing and freezing. Avian attacks often provoke fleeing to shelter in the Belding's ground squirrel (Spermophilus beldingi) (Turner 1973) or in rabbits (Oryctolagus cuniculus) (Vitale 1989). A similar finding was described by Taraborelli et al. (2007) who tested the antipredator behaviour of wild cavies (Microcavia australis) in the natural environment in Argentina. When confronted with a fake raptor, wild cavies showed high frequencies of fleeing and vigilance. This observation took place in one wide area with short herbaceous cover. In nature, antipredation behaviour is related to the structure of vegetation (e.g. Ebensperger and Hurtado 2005; Taraborelli et al. 2007). Foraging in short vegetation should increase the probability of detecting predators (Cassini and Galante 1992). In nature, flying predators are detected as shadows on the ground (Taraborelli 2006). During our experiments, artificial lights were used; they allowed the guinea pigs to see the fuzzy shadow made by the fake raptor as well. Guinea pigs reacted by trying to flee to a shelter, even if it was not provided, and froze.

Moreover, we detected differences in reactions in presence of the bird of prey between males and females. Duration and frequency of fleeing was higher in females compared to males. This was described by Stankowich (2008) who observed sex differences in reactions of ungulates and came to the conclusion that females are more wary of predators than males. He suggested that the benefit of fleeing is more relevant for females because of their reproductive potential and protection of offspring.

The polygynous social system is of great importance in guinea pigs. In groups with a higher number of females there is also a greater risk of being predated for them; thus the females may be under greater pressure to hide and protect their reproduction potential (Stankowich 2008).

Although Cavia sp. (Caviidae) often display alarm calls (Cassini 1989), the occurrence of alert calls in our experiment was quite accidental. According to Berryman (1976), this result is not surprising because domestic guinea pigs rarely emit alarm calls. Moreover, during observations of wild cavies in nature (Cavia aperea), Trillmich et al. (2003) did not note the emitting of alarm calls when a predator was encountered. Neither did Microcavia australis emit alarm calls when detecting a predator (Taraborelli et al. 2007; Taraborelli 2008) in the natural environment. The almost no occurrence of warning calls in our trials may have been caused by the absence of other guinea pigs. A testing for acoustic warnings of domestic guinea pigs in a group and comparing them with outcomes of this study would be of interest.

In conclusion, our results provide evidence that domestic guinea pigs can discriminate aerial types of predators from the terrestrial ones even under laboratory conditions when exposed to them individually. 


\section{Acknowledgements}

We express our thanks to Irena Schneiderová, Richard Policht, Lukáš Jebavý (in memoriam), Lukáš Sobota, Renata Masopustová, Ivana Giardianová, Pavel Štarha, and Veronika Strnadová and her dog Panda. This research received no specific grant from any funding agency in the public, commercial, or not-for-profit sectors.

\section{References}

Apfelbach R, Blanchard CD, Blanchard RJ, Hayes RA, McGregor IS 2005: The effects of predator odors in mammalian prey species: a review of field and laboratory studies. Neurosci Biobehav R 29: 1123-1144 Arvola A 1974: Vocalization in the guinea-pig, Cavia aperea f. porcellus. Ann Zool Fenn 11: 1-96

Asher M, Spinelli de Oliveira E, Sachser N 2004: Social system and spatial organization of wild guinea pigs (Cavia aperea) in a natural population. J Mammal 85: 788-796

Berryman JC 1976: Guinea pig vocalizations: their structure, causation and function. Z Tierpsychol 41: 80-106

Blanchard RJ, Flannelly KJ, Blanchard DC 1986: Defensive behaviour of laboratory and wild Rattus norvegicus. J Comp Psychol 100: 101-107

Blanchard RJ, Blanchard DC, Rodgers J, Weiss SM 1990: The characterization and modelling of antipredator defensive behaviour. Neurosci Biobehav Rev 14: 463-472

Brown G, Ferrari M, Elvidge C, Ramnarine I, Chivers D 2013: Phenotypically plastic neophobia: a response to variable predation risk. Proc R Soc B 280: 2012-2712

Cassini MH 1989: El comportamiento alimentario de los Cavias (Mammalia, Rodentia) y la "Teoría de forrajeo óptimo". Doctoral thesis in Biological Sciences. UBA, Argentina, 218 p.

Cassini MH 1991: Foraging under predation risk in the wild guinea pig (Cavia aperea). Oikos 62: 20-24

Cassini MH, Galante ML 1992: Foraging under predation risk in the wild guinea pig: the effect of vegetation height on habitat utilization. Ann Zool Fenn 29: 285-290

Coulon J 1982: La communication acoustique du cobaye domestique: comparaison avec quelques rongeurs. J Psychol 1: 55-78

Csányi V, Tóth P, Altbäcker V, Dóka A, Gervai J 1985: Behavioural elements of the paradise fish (Macropodus opercularis). II. A functional analysis. Acta Biol Hung 36: 115-130

Curio E 1976: The ethology of predation. Springer-Verlag, Berlin, 90 p.

Ebensperger LA, Hurtado MJ 2005: On the relationship between herbaceous cover and vigilance activity of degus (Octodon degus). Ethology 111: 593-608

Gallup GG Jr, Wallnau LB, Boren JL, Gagliardi GJ, Maser JD, Edson PH 1977: Tryptophan and tonic immobility in chickens: effects of dietary and systemic manipulations. J Comp Physiol Psychol 91: 642-648

Gambarotta JC, Saralegui A, Gonzáles EM 1999: Vertebrados tetrápodos del Refugio de Fauna Laguna de Castillos. Relevamientos de Biodiversidad 3: 1-31

Gladwin TE, Hashemi MM, van Ast V, Roelofs L 2016: Ready and waiting: Freezing as active action preparation under threat. Neurosci Lett 619: 182-188

Herre W, Röhrs M 1990: Haustiere - zoologisch gesehen. Gustav Fischer Verlag, Stuttgart/New York, 412 p.

Hollén LI, Radford AN 2009: The development of alarm call behaviour in mammals and birds. Anim Behav 78: 791-800

Hückinghaus F 1961: Vergleichende Untersuchungen über die Formenmannigfaltigkeit der Unterfamilie der Caviinae, Murray, 1886. Z Wiss Zool Abt A 166: 1-98

Klemm WR 2001: Behavioral arrest: in search of the neural control system. Prog Neurobiol 65: 453-471

Künzl C, Kaiser S, Meier E, Sachser N 2003: Is a wild mammal kept and reared in captivity still a wild animal? Horm Behav 43: 187-196

Lima SL 1987: Vigilance while feeding and its relation to the risk of predation. J Theor Biol 124: 303-316

Lima SL, Dill LM 1990: Behavioural decisions made under the risk of predation - a review and prospectus. Can J Zool 68: 619-640

Monticelli PF, Ades C 2011: Bioacoustics of domestication: alarm and courtship calls of wild and domestic cavies. Bioacoustics 20: 169-191

Monticelli PF, Ades C 2013: The rich acoustic repertoire of a precocious rodent, the wild cavy Cavia aperea. Bioacoustics 22: 49-66

Monticelli PF, Tokumaru RS, Ades C 2004: Isolation induced changes in guinea pig (Cavia porcellus) pup distress whistles. An Acad Bras Cienc 76: 368-372

Pettijohn TF 1979: Attachment and separation distress in the infant guinea pigs. Dev Psychobiol 12: 73-81

Pongrácz, P, Altbäcker V 1999: The effect of early handling is dependent upon the state of the rabbit (Oryctolagus cuniculus) pups around nursing. Dev Psychobiol 35: 241-251

Pongrácz P, Altbäcker V 2000: Ontogeny of the responses of European rabbits (Oryctolagus cuniculus) to aerial and ground predators. Can J Zool 78: 655-665

Rood JP 1972: Ecological and behavioural comparisons of three genera of Argentine cavies. Animal Behaviour Monographs 5: 1-83

Shahaf E, Eilam D 2003: Rodents in open space adjust their behavioral response to the different risk levels during barn-owl attack. BMC Ecol 3: 1-16 
Stankowich T 2008: Ungulate flight responses to human disturbance: A review and meta-analysis. Biol Conserv 141: $2159-2173$

StatSoft Inc. 2013. Statistica (Data Analysis Software System), Version 12. Available at: http://www.statsoft. $\mathrm{com} /$. Accessed May 10, 2016

Taraborelli P 2006: Factores que afectan la sociabilidad de Microcavia australis (Rodentia, Caviidae). Tesis doctoral. Universidad Nacional de Córdoba, Córdoba, 285 p.

Taraborelli P, Moreno P, Srur A, Sandobal AJ, Martínez MG, Giannoni AM 2007: Different antipredator responses by Microcavia australis (Rodentia, Hystricognate, Caviidae) under predation risk. Behaviour 145: 829-842

Taraborelli P 2008: Vigilance and foraging behaviour in a social desert rodent, Microcavia australis (Rodentia Caviidae). Ethol Ecol Evol 20: 245-256

Tokumaru RS 2000: Reconhecimento entre mãe-filhotena cobaia doméstica Cavia porcellus. Tese doutorado. Universidade de São Paulo, São Paulo, 115 p.

Trillmich F, Bieneck M, Geissler E, Bischof HJ 2003: Ontogeny of running performance in the wild guinea pig (Cavia aperea). Mamm Biol 68: 214-223

Turner L 1973: Vocal and escape responses of Spermophilus beldingi to predators. J Mammal 54: 990-993

Vitale AF 1989: Changes in the anti-predator responses of wild rabbits, Oryctolagus cuniculus (L.), with age and experience. Behaviour 110: 47-60

Vrba I, Donát P 1993: Activities (Computer Programme for Behavioural Studies).Version 2.1

Wing ES 1986: Domestication of Andean mammals. In: Vuilleumier F, Monasterio M (Eds): High altitude tropical biogeography. Oxford University Press, Oxford, pp. 246-264

Ximénez A 1980: Notas sobre el genéro Cavia Pallas com la descripción de Cavia magna (Mammalia: Caviidae). Revista Nordestina de Biologia 3: 145-179

Zipser B, Schleking A, Kaiser S, Sachser N 2014: Effect of domestication on biobehavioural profiles: a comparison of domestic guinea pigs and wild cavies from early to late adolescence. Front Zool 11:30 


\section{Plate VIII}

Baklová A. et al.: Antipredator behaviour ... pp. 293-301

A

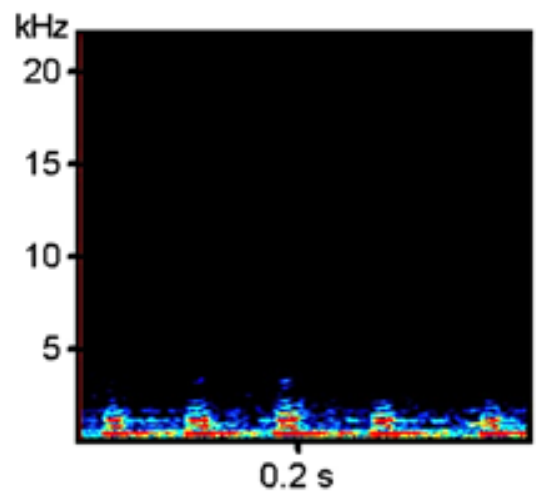

B

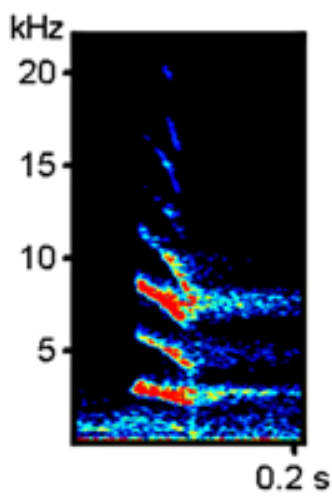

Fig. 4. Spectrograms of recorded sounds: A. Alarm call (drrr) - sound of one to four harmonics and low intensity and frequency composed of rapidly repeated units (Arvola 1974; Berryman 1976; Coulon 1982; Monticelli and Ades 2011); B. Alarm whistle (chirrup) - sound of high frequency composed of up to five repeated harmonic notes with marked frequency modulation (Berryman 1976; Pettijohn 1979; Tokumaru 2000; Monticelli et al. 2004). This call is based on an initial low whistle structure, which has been extended into a longer and higher frequency call (Berryman 1976). 